John D. Gallagher MD, David S. Smith MD PHD, Joan Meranze $\mathrm{MS}$, Susan Craig Nicolson MD, Rodolfo I. Godinez MD PHD

\title{
Aspiration during induction of anaesthesia in patients with colon interposition
}

The risk of aspiration during induction of anaesthesia in patients with oesophageal disease is not well defined, and controversy exists with respect to patients who have undergone pharyngeal-gastric colon interposition. Excellent gastrooesophageal competence has been documented in many of these patients, and propulsive peristalsis has been demonstrated in interposed colonic seg. ments, suggesting that aspiration risk is low. This report, however, describes recent anaesthetic experiences in two patients with colon interpositions and shows that these patients may have markedly redundant interposed seg. ments that retain food or other particulare residue and, thus, present a significant risk of particulate aspiration. Awake intubation may be the best approach to avoid aspiration in these patients.

Key words

COMPLICATIONS: aspiration; SURGERY: colon interposition.

Received from the Department of Anesthesia, University of Pennsylvania and Department of Anesthesia and Critical Care Medicine, Children's Hospital of Philadelphia, Philadelphia, Pennsylvania.

Address correspondence to: Dr. John D. Gallagher, Department of Anesthesiology, Deborah Heart and Lung Center, 1 Trenton Road, Browns Mills, New Jersey 08015 .
The risk of aspiration during anaesthesia in patients with pharyngeal-gastric colon interpositions has not been adequately described. Excellent gastrooesophageal competence $e^{1-3}$ and propulsive peristalsis of the interposed segment ${ }^{4}$ have been demonstrated in many of these patients and implies that aspiration risk is low. German and Waterston' did not find chronic aspiration to be prominent in their experience with 32 patients and $\mathrm{Lynn}^{2}$ suggested that gastrooesophageal incompetence is minimized with proper surgical technique. Benages et al. ${ }^{4}$ found manometric evidence of peristalsis in 13 of 15 patients with colon interpositions and suggested that these waves help propel colonic contents into the stomach and clear refluxed gastric juice from the interposed colon. In contrast, Lynn described the interposed segments as gravity dependent conduits with random, nonpropulsive muscular contractions. $^{2}$ While Rodgers et $a l .^{3}$ were unable to demonstrate postoperative gastrocolonic reflux using cinefluoroscopy, they demonstrated the absence of co-ordinated contraction and delays of two or more hours for passage of contrast material through interposed segments.

We recently anaesthetized two patients who had previously undergone colon interposition. Although a rapid sequence induction and cricoid pressure were used, one patient aspirated. Deviation of the oesophageal-colonic junction and the high anastamotic level apparently made cricoid pressure ineffective. In addition, both patients showed roentgenographic evidence of markedly dilated and tortuous interposed colonic segments. The existence of this dilated structure suggests that it may contain partially digested particulate residue and oral microflora. ${ }^{3}$ Despite evidence of gastrooesophageal competence in many patients with 
colon interposition, ${ }^{1-3}$ a risk of aspiration of retained oesophageal (colon) contents exists.

\section{Report of cases}

\section{Case I}

A 5-year-old $17 \mathrm{~kg}$ boy required exploratory laparotomy for small bowel obstruction. At age six weeks his congenital oesophageal atresia was repaired with a right colon interposition. A complicated postoperative course due to leakage at the proximal anastamosis resulted in mediastinitis, pneumonitis, and respiratory failure requiring tracheostomy, prolonged ventilatory support, and, eventually, decortication of the right lung. Because of an inability to control secretions and recurrent aspiration pneumonia, a cervical oesophagostomy was performed. Alimentation was accomplished via gastrostomy. By the age of three years, ventilatory support had been discontinued and the tracheostomy was removed. At age 4.5 years the original colon interposition, severely strictured due to the mediastinitis, was excised and a twa-stage procedure was performed interposing an isoperistaltic segment of transverse colon retrostemally. Six months later, abdominal pain and distension with vomiting and dehydration occurred. A barium contrast oesophagram confirmed the patency of the colon interposition and emergency exploratory laparotomy was planned. Vital signs were normal and the physical exam was notable for ballooning of the right side of the neck when the patient cried. After monitoring was established and an intravenous cannula placed, the stomach contents were drained via the gastrostomy. Atropine $0.4 \mathrm{mg} \mathrm{IV}$ was given and the patient breathed 100 per cent oxygen for five minutes. Because of poor patient co-operation an awake intubation was not attempted. With the patient supine, pancuronium 0.15 $\mathrm{mg} \cdot \mathrm{kg}^{-1}$ followed by ketamine $2 \mathrm{mg} \cdot \mathrm{kg}^{-1}$ were given intravenously. Cricoid pressure was applied by an experienced anaesthesiologist throughout the induction. With laryngoscopy the anaesthesiologist found the pharynx full of barium-coloured fluid. The pharynx was suctioned and the trachea intubated. Anaesthesia was maintained with oxygen, fentanyl, halothane, and pancuronium. On completion of the surgical procedure, which consisted of lysis of abdominal adhesions, the patient was brought to the intensive care unit. Postoperative chest $X$-ray showed distortion of the right chest wall due to the prior decortication, and a dilated $(2.5 \mathrm{~cm}$ diameter), tortuous colon segment extending from pharynx to stomach. This colonic segment contained pockets of retained barium. Rightward deviation of the interposed colon in the neck was observed. Aspiration was confirmed radiographically by observing barium in the tracheobronchial tree. Respiratory insufficiency necessitated continued intubation for four days and supplemental oxygen by mask for a week following extubation.

Three months following discharge, the patient returned to the hospital for dilation of a strictured colon interposition. With the known underlying lung disease, the past history of aspiration on induction, and the strong suspicion that the colonic pouch contained particulate matter, a decision was made to intubate the patient awake in a head-up position. In the operating room, monitoring was established and an intravenous cannula was inserted. The patient received $0.3 \mathrm{mg}$ of scopolamine and incremental doses of diazepam (total dose $5 \mathrm{mg}$ IV). Upon laryngoscopy, the pharynx was noted to be filled with particulate matter suspended in fluid. Intubation was accomplished and aspiration of this material did not occur. The surgical procedure proceeded without incident. Scopolamine was reversed with physostigmine I $\mathrm{mg}$ IV and the patient was discharged to home on the day of the procedure.

\section{Case II}

A 27-year-old woman with syringomyelia and syringobulbia presented with segmental upper extremity weakness, sensory deficits, and left vocal cord paralysis due to brainstem compression from the expanding bulbar syrinx. A thoracic laminectomy and syringo-pleural shunt implantation were planned. Sixteen years earlier an oesophagectomy and partial gastrectomy with colon interposition had been performed to control bleeding from oesophagogastric varices. Three times during the next ten years aspiration pneumonitis not associated with anaesthesia and surgery occurred due to glottic incompetence. Examination revealed a thin, $38 \mathrm{~kg}$, $157 \mathrm{~cm}$ female. Diagnostic studies included a contrast oesophagram (Figure) which demonstrated marked redundancy of the colonic segment with pockets of retained barium (arrow) and suggested that the patient was at risk of aspiration from 


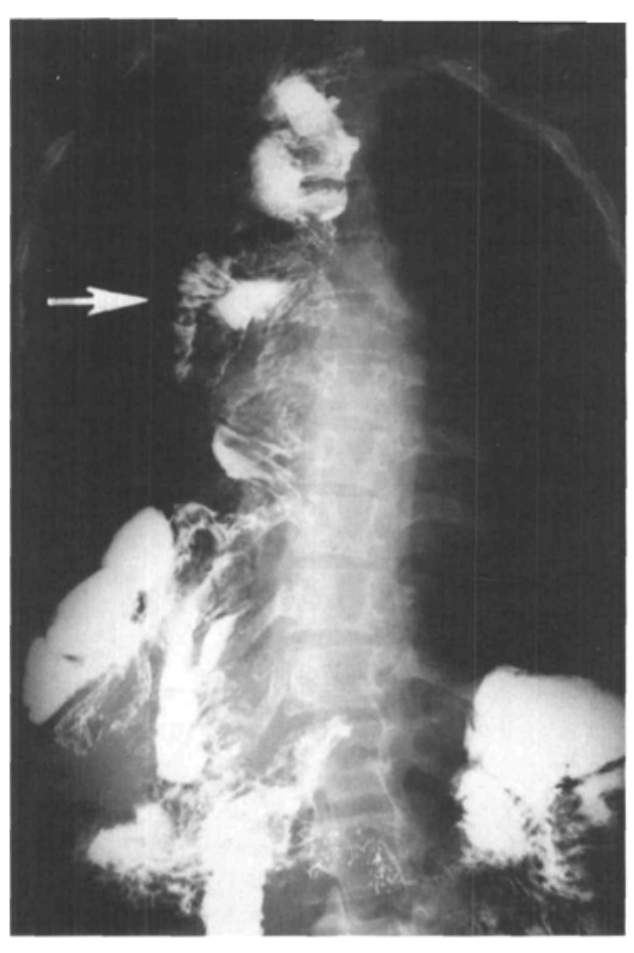

FIGURE A barium "oesophagram" (posterior-anterior view) from Patient II with an arrow pointing to a large dilated interposed colonic segment in the thorax and pockets of retained barium.

retained oesophageal contents during induction of anaesthesia.

The presence of the expanding brainstem lesion placed this patient at risk for increased intracranial pressure secondary to the coughing, straining or hypertension that might occur during an awake intubation. ${ }^{5}$ Though difficult to predict for a given patient, this increased intracranial pressure might be severe enough to produce permanent damage to the brain or cardiovascular collapse. Consequently, an awake intubation was not used and induction of anaesthesia was designed to try to avoid both increases in intracranial pressure and cerebral blood flow, and aspiration. In the operating room, monitoring was established. After administration of oxygen by mask, the patient was placed 25 degrees head up and asked to voluntarily hyperventilate. Meperidine $50 \mathrm{mg}$ IV was given, cricoid pressure was applied, and thiopentone $5 \mathrm{mg} \cdot \mathrm{kg}^{-1} \mathrm{IV}$, followed by pancuronium $0.15 \mathrm{mg} \cdot \mathrm{kg}^{-1}$ IV were administered. The trachea was intubated without difficulty. Regurgitation did not occur and anaesthesia was maintained with nitrous oxide and incremental doses of thiopentone and meperidine. At the completion of surgery, the patient was transferred to the intensive care unit where her trachea was extubated without incident.

\section{Discussion}

In our patients, an awake intubation for Patient I would have been preferable for airway protection. However, patient agitation and lack of co-operation before the exploratory laparotomy disuaded those caring for the patient. Despite drainage of gastric contents via the gastrostomy, and a "rapid sequence" induction with properly applied cricoid pressure, aspiration of oesphageal material occurred. In retrospect, deviation and dilation of the colon in the neck probably decreased the effectiveness of cricoid pressure. A head-up position during induction may have reduced the risk of regurgitation. When the patient returned to the operating room, a semi-awake intubation was performed. Although the pharynx was found filled with foreign matter, aspiration did not occur.

The coexistence of laryngeal incompetence due to the expanding bulbar syrinx in our second case compounded the risk of aspiration. Knowledge of the colon's redundancy and the possibility of retained material suggested that an awake intubation would be preferred. However, the existence of an expanding, space occupying central nervous system lesion led us to use a "rapid sequence" induction with a large dose of thiopentone to minimize possible increases in intracranial pressure, that might have occurred in this patient had she coughed or otherwise responded to an attempted awake intubation. ${ }^{5}$ Cricoid pressure and head-up tilt were chosen to decrease aspiration risk.

Although suction of the interposed colon and stomach may diminish the volume and likelihood of aspiration, ${ }^{6}$ we felt nasogastric intubation was contraindicated in the first case because of poor patient co-operation and excessive psychological stress, and in the second case because of the patient's decreased cerebral compliance.

Nine per cent of patients with documented aspiration pneumonia have associated oesophageal motility disorders. ${ }^{7,8}$ The contrast between the high 
incidence of chronic aspiration in children following one-stage repair of oesophageal atresia ${ }^{9}$ and the remarkably low incidence of aspiration (1 of 40) following colon interposition in children with oesophageal atresia, ${ }^{1}$ oesophageal varices, ${ }^{2}$ or intractable strictures ${ }^{1}$ suggests effective peristalsis in many patients with colon interposition. ${ }^{4}$ Despite this evidence, our experience suggests that interposed segments may be tortuous, dilated, and serve as a reservoir for retained material. Since the volume and emptying time of retained oesophageal material cannot be ascertained easily preoperatively, and since standard approaches to airway protection during the induction of anaesthesia may not be efficacious, we emphasize that patients with colon interposition are at risk of aspiration and should be intubated awake when other factors allow. If awake intubation is impractical, gentle suction of the colon interposition before induction and the use of headup tilt may be helpful. Cricoid pressure during induction, especially if the interposed segment is not deviated from midline, is appropriate. Strict proscription of oral intake of solid foods for at least the day preoperatively may decrease the amount of particulate residue in the colon interposition.

\section{References}

1 German JC, Waterston DJ. Colon interposition for the replacement of the esophagus in children. J Pediatr Surg 1976; 11: 227-34.

2 Lynn $H B$. Colon interposition in pediatric patients with esophageal varices. Ann Surg 1971; 73: 706-13.

3 Rodgers BM, Talbert JL, Moazam $F$ et al. Functional and metabolic evaluation of colon replacement of the esophagus in children. J Pediatr Surg 1978; 13: 35-9.

4 Benages A, Moreno-Ossett E, Paris F et al. Motor activity after colon replacement of esophagus. J Thorac Cardiovasc Surg 1981; 82: 335-40.

5 Shapiro $H M$. Intracranial hypertension. Therapeutic and anesthetic considerations. Anesthesiology 1975; 43: 445-71.

6 Bannister WK, Sattilaro AJ. Vomiting and aspiration during anesthesia. Anesthesiology 1962; 23: 251-64.

7 Cameron JL, Mitchell WH, Zuidema GD. Aspiration pneumonia. Clinical outcome following documented aspiration. Arch Surg 1973; 106: 49-52.

8 Tinstman TC. Dines DE. Arms RA. Postoperative aspiration pneumonia. Surg Clin North Am 1973; 53: 859-62.

9 Chrispin AR, Friedland GW, Waterston DJ. Aspiration pneumonia and dysphagia after technically successful repair of oesophageal utresia. Thorax 1966; 21: 104-10.

\section{Résumé}

Le risque d'aspiration durant l'induction de l'anesthésie chez les malades porteurs de pathologies oesophagiennes n'est pas bien connu; de plus, on ne s'entend pas sur celui que présentent les malades qui ont subi une interposition pharyngo-gastrique du colon. D'un côté, on a montré chez plusieurs de ces malades une excellente fonction gastro-oesophagienne de même qu'on a mis en évidence une activité péristaltique propulsive dans ces segmens de colon. Ces deux éléments amènent à croire que le risque d'aspiration est minime. Cependant, nous rapportons ici des incidents anesthésiques chez deux patients porteurs d'interposition colique. Ces incidents montrem que certains de ces "nouveaux oesophages" peuvent présenter des tortuosités où stagnent des résidus alimentaires. Ceci représente un risque réel d' aspiration de particules solides. L'intubation pré-induction constitue peut-être la façon la plus prudente chez ces malades. 